\title{
Towards electronic learning features in education 4.0 environment: literature study
}

\author{
Nor Azah Mansor, Natrah Abdullah, Hayati Abd Rahman \\ Department of Computer and Mathematical Sciences, Universiti Teknologi Mara (UiTM) Shah Alam, Malaysia
}

\begin{tabular}{l} 
Article Info \\
\hline Article history: \\
Received Nov 15, 2019 \\
Revised Jan 10, 2020 \\
Accepted Jan 30, 2020
\end{tabular}

\section{Keywords:}

e-learning

Higher education institution

Industry 4.0

Online learning

Teaching and learning

\begin{abstract}
This paper presents electronic learning features in Education 4.0 environment. Malaysian government encourages Higher Education Institution (HEIs) to embed technologies in order to prepare future education (Education 4.0). Besides, developing skills among students is important to be more adaptable in changing the environment. Current HEIs using Learning Management System (LMS) has lack of interactive features and non-personalized learning. Therefore, this article set out to analyze the existing literature on e-learning practices in Education 4.0 and to propose e-learning features suits in Education 4.0 environment. Guided by the PRISMA Statement (Preferred Reporting Items for Systematic reviews and Meta-Analyses) review method, a systematic review of the Scopus 24 related studies. Further review of these articles resulted in seven principles of e-learning features based on the constructivism principle - Self-regulation, Personal perspective, Experiential learning, Social learning, Learning Community, Creating and Sharing Knowledge, Structure and layout which can be used to upgraded and redesigned LMS.
\end{abstract}

Copyright @ 2020 Institute of Advanced Engineering and Science. All rights reserved.

\section{Corresponding Author:}

Nor Azah Mansor,

Department of Computer and Mathematical Sciences,

University Technology Mara (UiTM),

40450 Shah Alam, Selangor.

Email: azahmsr@gmail.com

\section{INTRODUCTION}

The Fourth Industrial Revolution (4IR) environment is affecting production and services including education system. In line with 4IR, higher education institutions (HEIs) are encouraged to embed technology in Education 4.0. The Education 4.0 environment implements a smart campus that includes dynamic learning, high creativity, conducive classrooms and green technology. Rapid changes in technology concerning 4IR require more challenging for HEIs to sustain in providing necessary skills to adapt such changes in the market. The Malaysian Education Blueprint 2015 to 2025 stresses on ten skill sets, which entail complex problem solving, critical thinking, creativity, people management, coordinating with others, emotional intelligence, judgement and decision making, service orientation, negotiation and cognitive flexibility [1]. These skill sets are important to be applied in Education 4.0 because the learning process changes from teacher centred to adaptive learning. Students become active participants to achieve their personal goals. Personal goal success relies upon their course interest, options of instructional method, capability and academic support strategies. This shift in the learning process needs to be parallel with the teaching method. Teaching method approaches that are based on personalised learning embed electronic learning (e-learning) and integration with several Artificial intelligence (AI) applications. This approach advocates students to remain engaged in the best learning process. 
The current teaching and learning method in Malaysia's HEIs is blended learning, which is a combination of conventional learning and e-learning. However, conventional learning (face to face) and e-learning in HEIs has lack in interactive nature of the digital technology. The standardised curriculum in HEIs does not cater to students need because of pedagogy did not change according to education 4.0. HEIs should providing AI-driven high; breakdown of national, regional, and HEIs boundaries. Education 4.0 encourage students to plan their education guided by educator and AI help. Millennial generation prefer high familiarity with Internet technology usage especially social media, and smartphones [2]. This is one of the advantages for them to utilise social media platforms for learning purposes. Conventional learning is refers to face-to-face learning using a fixed location and specific time.

Electronic learning provided by HEIs is called learning management system (LMS). LMS functions to create, share, respond, evaluate, administer, monitor, and manage the delivery of the learning content [3, 4]. LMS contains several modules, namely;- (i) user management module for managing students; (ii) course management module; (iii) resource module for maintaining files so that they are always updated; (iv) lesson module for organizing hierarchy, managing assignments and quizzes; (v) news module; (vi) messaging module for individuals and groups; and (vii) calendar and blog module for adding or sharing events [3]. There are many types of e-learning other than LMS provided by HEIs such as learning websites, social media platforms and social networking sites. The most popular e-learning platforms to promote learning are YouTube, LinkedIn, Twitter, Facebook and Google+ [5]. E-learning encourages self-learning due to flexible time, location and adequate resources. E-learning can be divided into two types; namely asynchronous and synchronous e-learning. Asynchronous e-learning means unreal-time interaction; nevertheless, students can access resources at any time. Meanwhile, synchronous e-learning involves real-time interaction between people such as activities and discussions in online chat rooms, livestreaming and online games.

In preparing the environment for Education 4.0, personalised learning should be considered. Presently, conventional learning does not support personalised learning. LMS offered by universities is lacking in terms of interactive features. Students become bored when using e-learning due to the ease of use of the platform [6]. Students choose to learn in a comfortable and familiar environment. Therefore, the government fosters HEIs to utilise e-learning in teaching and learning as a supplementary method for LMS. This paper used systematic literature review as the methodology. To construct a relevant systematic review, the current article was guided by two research objectives. First is to identify the teaching and learning environment for Education 4.0. Second is to identify the electronic learning features. Electronic learning features in Education 4.0 environment was proposed. Constructivism principles had been adapted with the e-learning features in order to improve the current education system. Constructivism means every learner construct meaningful knowledge individually and socially from experience [7]. Constructivism applies both learning theory and to the nature of knowledge and learning [8]. Learning theory include descriptive learning theory and prescriptive learning theory. Descriptive learning theory focuses on how learning occurs. Descriptive learning provides a description and explanations of the processes of education. The common categorization that distinguishes between behaviourist, cognitive, and constructivist learning theory. Prescriptive learning theory often based on descriptive theory, sometimes they are derived from experience. Prescriptive learning theory focus on methods of instruction for teaching curricula. Following are principle of constructivism theory [9]. First is encourage self-autonomy and control it, make instruction relevant to their own self. Second, create a learning context that supports the development of self-autonomy by interdependence it. Next, giving students reason to learn in carrying out learning activities. Support self-regulation by encouraging the development of skills and attitudes to enable students to be more responsible for self-learning. Lastly, encourage intentional learning and checking offenses. Learning consists of individuals' constructed meanings; [10] list down ninth constructivism principle as following:

a) First, student need to be an active learner by engaging with world.

b) Student will be constructing system of meaning.

c) Constructing system of meaning involve both physical and mental actions.

d) Language also important to make sure students understand and comfortable while communications.

e) Learning is a social activity: we need to realize that students learn something by doing it individually and in social activity.

f) Learning is contextual. Knowledge are created from face to face and e-learning must be interpreting

g) into practical.

h) One needs knowledge to learn: Knowledge needs to be connected from previous to create new knowledge. Educator must ensure teaching and learning is compatible with students' knowledge.

i) Educator play as a mentor to guide and monitor students along this learning process.

j) Self-motivation is important to make sure learning goal achieve. 
This paper present electronic learning features in Education 4.0 environment. As such, blended learning actively pursued. This will enable greater dynamism and personalisation of students' learning experience. This paper contributes on criteria Education 4.0 in blended learning environment. After that, features learning in e-learning are identified to make sure that it is relevant to education 4.0.

\section{RESEARCH METHOD}

In this section, the method used to retrieve articles related to electronic learning in industry 4.0 environment is discussed. The reviewers used PRISMA, which includes resources (Scopus) used to run the systematic review, eligibility and exclusion criteria, steps of the review process (identification, screening, and eligibility) and data abstraction and analysis. The review was guided by the PRISMA Statement (Preferred Reporting Items for Systematic Reviews and Meta-Analyses). PRISMA is often utilized within the environmental management field. Systematic literature review offers three unique advantages which are 1) defining clear research questions that permit a systematic research; 2) identifying inclusion and exclusion criteria; and 3) attempting to examine a large database of scientific literature in a defined time. This research used systematic literature review from the Scopus database [11]. The Scopus database was chosen as it as one of the largest abstracts and citation databases of peer-reviewed literature with more than 23,500 journals from 5000 publishers worldwide. There are three phases in systematic literature review. The first phase is identification. Table 1 shows the first phase on systematic literature review which is keyword searching data using phrase searching, wildcard and truncation. Keywords are defined from the research objectives, the similarity of words and also keywords on previous articles.

Table 1. Keywords and information search strategy

\begin{tabular}{cll}
\hline Database & \multicolumn{1}{c}{ Research Objective } & \multicolumn{1}{c}{ Keywords Used } \\
\hline Scopus & To identify Education 4.0 & TITLE-ABS-KEY ( ( "industr* revolution" OR "IR" ) AND ( industr* AND \\
& environment. & revolution 4.0 OR ir 4.0 ) AND education AND teaching AND learning ) \\
Scopus & To identify electronic learning & TITLE-ABS-KEY ( ( "electronic learning" OR "online learning" OR "digital \\
& features in Education 4.0 & learning" OR "virtual learning" OR "e-learning" ) AND ( "social media" \\
& environment & OR "social learning" ) AND ( "higher education institution" OR universit* \\
& & OR hub ) AND teaching AND learning AND education ) \\
\hline
\end{tabular}

Figure 1 is flowchart of screening process starting from identification using keyword in Table 1. The result showed that in the Scopus database, for Objective One (N1) had 18 articles. As for Objective Two (N2), there were is 160 articles in Scopus. The second phase is screening works limit on open access subscribed by university. The open access subscribed by university in the Scopus database, for N1 had 11 articles but only 20 articles for N2. The screening phase considers the inclusion and exclusion criteria. Excluded area involve only N2. Six articles need to exclude which are two articles non-English and four articles more than 5 years. Total records after screening for N2 is 14. The remaining articles fitted the criteria after the screening process was performed. The last phase is eligibility. This process conducted manually by the authors. Eligibility process only accept subject related on education field. Filtering is done by looking at the abstract and analyzing article objectives. One article from N1 need to exclude because of oil and gas field. The total accepted paper for N1 to review is 10. A total of 24 articles have been extracted as much as three phases (Identification, Screening and Eligibility). After screening process on 24 articles, data were analyze using Thematic Analysis based on frequency to produce findings that have the potential to explain the theme of learning features in the era of the 4.0 Industrial Revolution. 


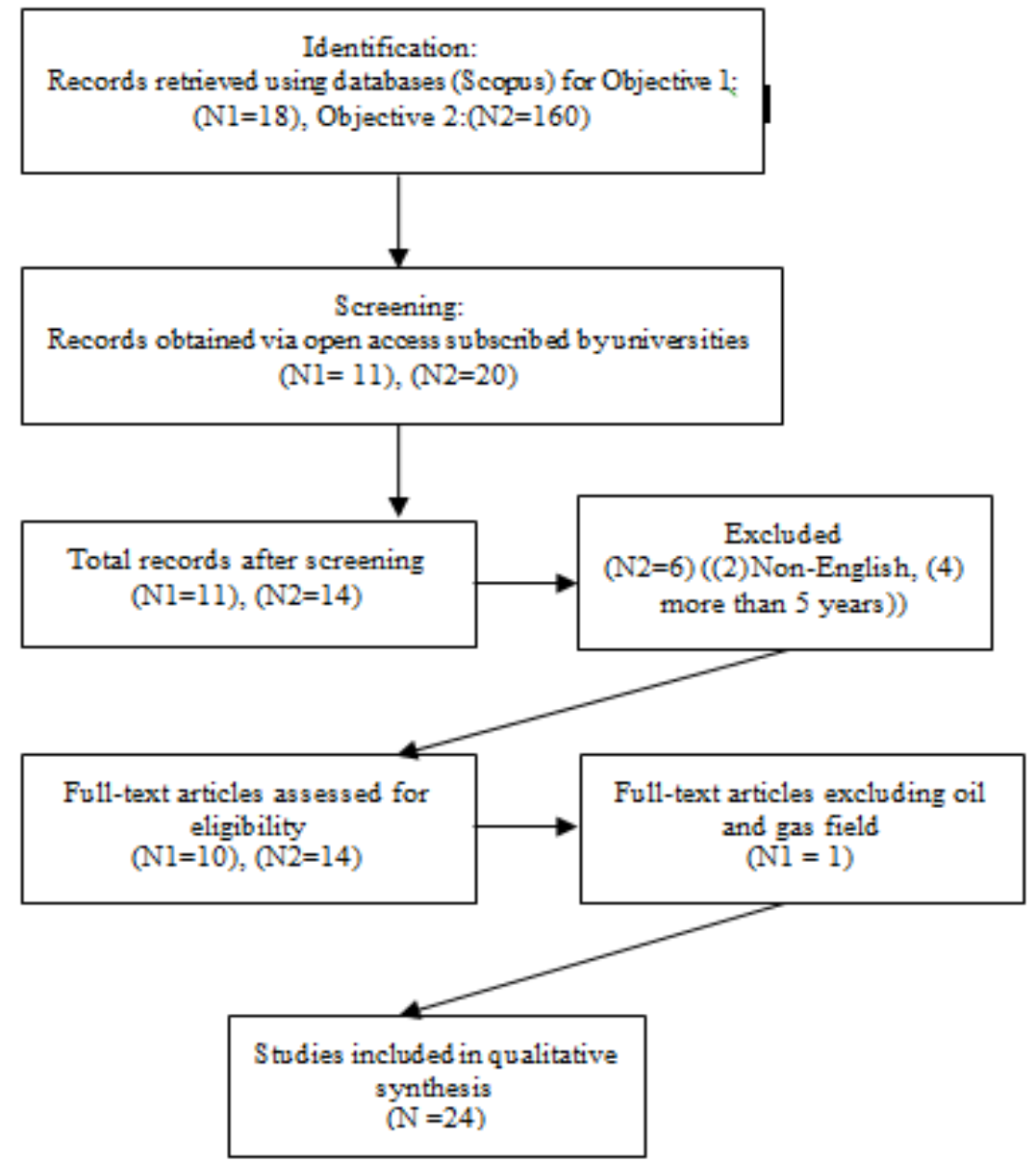

Figure 1. Screening process of related articles

Highlight propose method (procedures)

\section{LITERATURE STUDY}

\subsection{Education 4.0 environment}

There are 11 criteria of teaching and learning identified in multi-disciplinary courses carried out in Education 4.0. Education 4.0 commonly use Information and Communication Technology (ICT) to aid the teaching and learning process so as to enhance understanding among students. The criteria are as Table 2: experiential learning, free and convenient access, location and time independent, allow to access dynamic resources, culture, interactive teaching material and media, real-time control system, language, social learning, self-regulation and safety system. Experiential learning helps students to construct knowledge by several project-oriented learning methods. They learn how to handle equipment using a real-time control system without worrying about their safety because there is no physical contact with the machine [12].

Experiential learning is the most effective because students apply facts into practice. Repetitive activities during practical learning preserve the knowledge in spatial memory. Education 4.0's environment teaching and learning approaches use electronic learning as the medium in delivering information. Electronic learning allows free and convenient access to dynamic resources. By applying technologies, the teaching and learning process becomes interactive. Technologies using in education 4.0 such as autonomous robots, simulation, system integration, Internet of Things, cybersecurity, cloud computing, additive manufacturing, augmented reality and Big Data that need to be applied or perform or incorporated to the curriculum preparation and implementation in the university [13]. Teaching materials in Education 4.0 consist of visual teaching materials, audio teaching materials, audio-visual teaching materials, computer-assisted instruction (CAIs), interactive multimedia teaching materials, compact disks (CDs) multimedia interactive learning, web-based teaching materials [14]. 
Other criteria in Education 4.0 environment are social learning, which can be obtained from problem solving, informal communication skills, learning experiences and active learning $[12,15,16]$. Social learning involves communication, response, collaboration, discussions with peers, educators and experts, professional networking and online community. Peer collaboration is important to achieve a common goal, show sensitivity to diverse cultures, build trust when having a discussion, compromise and give respect [17]. This opportunity aids students in learning to take their own grasp on planning, measuring, observing, revising, and finalizing their projects [18]. In the end, students feel more confident and this increases their motivation. Unsurprisingly, culture and language are found to less important in Education 4.0 environment because Malaysia commonly uses English as a second language. Therefore, students have the ability to communicate with foreigners and can quickly adapt to other cultures. Table 2 shows an analysis of teaching and learning in Education 4.0 environment.

Table 2. Teaching and learning in education 4.0 environment

\begin{tabular}{lcc}
\hline \multicolumn{1}{c}{ Criteria } & Definition & Authors \\
\hline Experiential learning & Knowledge construction & {$[12,15-17,19-22]$} \\
Free and convenient access & Resources easy access & {$[12,15,23]$} \\
Location and time independent & Flexibility & {$[12,14-16,20]$} \\
Allow to access dynamic resources & Creating and Sharing & {$[14,15,20,21,23]$} \\
Culture & Learning culture & {$[17]$} \\
Interactive teaching material and media & Technology adapt to the needs & {$[12,14,15,19-23]$} \\
Real-time control system & Real-time & {$[12,14]$} \\
Language & Communication & {$[15]$} \\
Social learning & Interaction & {$[12,14-17,19-23]$} \\
Self-regulation & Individualized learning & {$[19-23]$} \\
Safety system & Security & {$[12]$} \\
\hline
\end{tabular}

\subsection{Electronic learning features in Education 4.0 environment}

The second objective aims to design the appropriate teaching and learning environment that effectively incorporate technology needs between educators and students. Table 3 indicates an analysis of electronic learning features. The most important features in e-learning are flexibility, free and convenient access, social learning and private group. Flexibility refers to teaching and learning delivery that can occur anytime and anywhere. Flexible in learning helps students to find their own learning styles. Dynamic learning resources assist students to choose free resources that can be conveniently accessed. E-learning offers interactive features for communication, sharing knowledge and dissemination of information [24]. From that, knowledge is constructed by selective information and forms into knowledge patterns. The ability of students to create knowledge helps self-regulation skills. Knowledge is generated to develop human expertise [18]. Students improve their self-regulation skills via self-learning and social learning. Students should apply active learning by utilising several platforms such as LMS, online databases, learning websites and social media platforms to find information in increasing knowledge and building multiple skills. Then, using the knowledge, students can apply it in many learning activities such as discovery learning, problem solving, industry problem based-project [13], research-based learning, collaborative learning [25] and cooperative learning.

As a result, students become responsive towards their learning environment. These concepts are aligned with the constructivism principles which has been discuss in chapter one where students actively construct their knowledge through experience and interaction with persons, objects and situations $[8,26]$. There are nine constructivism principles of learning [10]. First, learning is an active process. Students actively construct knowledge based on current or past knowledge. Second is people learn to learn as they learn. Every student has their own capacity to process information. Repetitive actions help them in their learning to understand and memorize. Third, mental is an essential action in constructing meaning. Constructivism encourages self-autonomy and self-control over the flow of the lesson, making instructions relevant to one's own self [9]. Fourth is learning involves language, which means learning in their own language. Fifth, learning is a social activity. Connections with other individuals such as lecturers, peers, family and non-recognized people. Sixth, learning is contextual. Active students can construct knowledge for themselves. Students discover information so that they can excel in the concept of learning. Seventh, one needs knowledge to learn. Eight is students take time to learn. Students have their own learning goal and learning path. Ninth is motivation; - whereby motivation is vital for learning. There are two parts in student motivation [27]. First is intrinsic student motivation, where students participate in an activity "for their own sake" and accomplish the task given with joy. Second is extrinsic student motivation, which is obtained from 
rewards, grades and teacher approval. Students who are motivated to learn gain meaningfulness, value, and benefits of academic tasks.

Using private groups as a safety measure will help educators to ensure students enter a secure digital space. A private group is a small learning community there is less didactic lecture-based teaching. LMS has more privacy and is secure because of the maintenance provided by universities. Safety in e-learning private group context only covers recognized participants and content sharing. Participants in the private group need to obtain permission from educators if they want to create and share content. The validation process by educators is to ensure the information is reliable, relevant and accurate. The creation of groups and interactions among peers and educators help them to easily access the syllabus. Communications among them become active, leading to a better engaged and motivating students to become productive [28]. Communications tend to be joyful and entertaining. Another learning feature in e-learning is alert system. Educators can alert group members for a test date or the time of completion of a task.

Education 4.0 allows pedagogical changes, moving from lecturing towards tutoring and mentoring [29]. Pedagogy concerns with content, participants and media analysis. Content in e-learning must be updated with current knowledge, reliable multimedia files, relevant and accurate resources before sharing. Numerous tools in e-learning can enhance and support pedagogy [18]. The advantages of using several tools are students gain understanding because of the multiple presentations and tools such as visual, graphic, animation, print, audio and video. Educators can track students' development through the tools they are using. As a result, educators are able to know the level of students' knowledge and understanding, and perception while negotiating exchanges in a community, especially in communicating non-verbally. Teaching and learning materials must be multifaceted to allow students to express preferences. Therefore, the learning strategies should be suited as the students have different learning abilities [30]. Electronic learning offers dynamic resources that can help educators to personalise student learning. After reviewing literature in a five-year period on 2015 until 2019, it was found that there are 15 learning features that have an impact towards e-learning development, which are displayed in Table 3. According to the mapping element below, the result showed that the major elements consist of flexibility, free and convenient access, social learning and private group. Therefore, these variables will be compulsory in developing e-learning.

Table 3. Electronic learning features

\begin{tabular}{|c|c|c|}
\hline Features & Definitions & Authors \\
\hline Social Learning & Interaction & {$[3,24,28,30-37]$} \\
\hline Creating and sharing resources & Dynamic resources & {$[3,18,24,28,30-38]$} \\
\hline Self-regulation & Reflective & {$[28,30-32,36]$} \\
\hline Relationship & Active & {$[3,24,28,31,32,34,35,38]$} \\
\hline Responsive & Immediate respond & {$[3,28,31,32,35,36]$} \\
\hline Private group & $\begin{array}{l}\text { Learning community environment to } \\
\text { facilitate knowledge creation and sharing }\end{array}$ & {$[3,24,28,30-32,34-37,39]$} \\
\hline Knowledge construction & Capability & {$[3,18,28,30,31,33,34,37,38]$} \\
\hline Culture and language & Build learning culture & {$[3,28,31]$} \\
\hline Structure and layout & $\begin{array}{l}\text { Pedagogy, adaptable with Education 4.0, } \\
\text { well-designed learning material }\end{array}$ & {$[3,18,28,31,33,35-37,39]$} \\
\hline Personal perspective & personalise, more private and closer & {$[3,18,24,31,33,35-38]$} \\
\hline Alert task & Awareness & {$[28,36]$} \\
\hline Self-motivation & Self-esteem & {$[3,28,32,39]$} \\
\hline Safety & Trustful connection & {$[28,33]$} \\
\hline Flexibility & Delivery, time and location, learning styles & {$[3,18,24,28,30,33-37,39]$} \\
\hline Free and convenient access & $\begin{array}{l}\text { Open source, constant connectivity, live } \\
\text { stream }\end{array}$ & {$[3,18,28,32-39]$} \\
\hline
\end{tabular}

\section{RESULT ON ELECTRONIC LEARNING FEATURES}

Table 4 proposes the e-learning features. The principles appealed to the authors' modern views of learning. The e-learning features matched with Education 4.0 as shown in Table 2. There is a need to reflect on the practices in order to apply these principles into the teaching and learning context. Self-regulation (P1) and experiential learning (P3) need to be combined. Students need to become active learners and construct knowledge from experiential learning. Each student is unique. Therefore, the teaching and learning process should consider personal perspective (P2). It is noted that individuals prefer different learning styles. Therefore, the capability of students to organize knowledge after gaining the resources is critical. There are various e-learning offered with free and convenient access such as Google Scholar, LinkedIn, Academia.com, YouTube EDU, iTunes U and Academic Earth. This e-learning needs to be integrated with LMS that lacks certain interactive method like graphic, video and imaging in order to enhance students' understanding. 
Teaching and learning through social learning (P5) and learning community (P6) should be integrated with social media platforms. The specific group created encourages students to become more focused on what needs to be discussed and educators can easily post multimedia files. There are a variety of social media platforms such as YouTube, Instagram, Facebook and Twitter. In social media, the conversations become more active and involve more members that are not recognized in real world. (P8) Structure and layout is a most important in designing the e-learning. To design a system, need a good programming so that it easy to secure the data and monitor [40]. Culture and language (P4) and self-motivation (P9) were not included as e-learning. Students feel resistant to accept new learning culture because of changing their role to proactive self-learning [13]. These two features need self-development and take more time to learn and adapt with new learning culture. The results from thematic analysis found that only seven are related to e-learning features:

Table 4. e-learning features

\begin{tabular}{cccc}
\hline $\begin{array}{c}\text { Principles } \\
\text { (P) }\end{array}$ & Constructivism Principle [10] & $\begin{array}{c}\text { e-learning features that match } \\
\text { with Education 4.0 }\end{array}$ & $\begin{array}{c}\text { Principle for e- } \\
\text { learning features }\end{array}$ \\
\hline P1 & Learning is an active process & Self-regulation & $\sqrt{ }$ \\
P2 & People learn to learn as they learn & Personal perspective & $\sqrt{ }$ \\
P3 & Mental is an essential action in & Experiential learning & $\sqrt{ }$ \\
P4 & constructing meaning & Culture and language & $\mathrm{X}$ \\
P5 & Learning involves language & Social learning & $\sqrt{ }$ \\
P6 & Learning is a social activity & Learning community & $\sqrt{ }$ \\
P7 & One needs knowledge to learn & Creating and sharing knowledge & $\sqrt{ }$ \\
P8 & It takes time to learn & Structure and layout & $\mathrm{X}$ \\
P9 & Motivation & Self-motivation & \\
\hline
\end{tabular}

\section{CONCLUSION}

This paper present electronic learning features in Education 4.0 environment using systematic literature review. This research was conducted to shed light on the features determining the success LMS in education, based on a constructivism principle. The existing teaching and learning in HEIs has lack interactive nature of digital technology. Thus, HEIs need to be upgraded and redesigned LMS according to suggested e-learning features in Table 4. Embedded e-learning features into LMS will help the educator to do learning strategy according to the student's capability and their learning styles. Redesign LMS must inject criteria education 4.0 to be reliable in the future. Future research recommendation is to do the experiment and readiness for education 4.0 environment. Researcher encourage to follow systematic literature review on several databases, thesis, newspaper and magazine articles based on keywords provided.

\section{ACKNOWLEDGEMENTS}

The authors would like to thank Universiti Teknologi MARA (UiTM), Malaysia for partly funding the study by given the GERAN INISIATIF PENYELIAAN (GIP) 600-IRMI 5/3/GIP (014/2019).

\section{REFERENCES}

[1] F. A. Majid, et al., "Toolkits for 21st Century Teaching: Practical Implications for the 4th Industry Skills Development," Kuala Lumpur: UiTM Press, 2017.

[2] W. N. A. W. Chik and L. Arokiasamy, "Perceived Higher Education Climate of Academics in Malaysian Private Institutions in Industry 4.0," Global Business and Management Research: An International Journal, no. 1, 2019.

[3] A. Al-Azawei, "What Drives Successful Social Media in Education and e-learning? A Comparative Study on Facebook and Moodle," Journal of Information Technology Education: Research, vol. 18, pp. 253-274, 2019.

[4] L. Bexheti, "Development of a learning content management system," WSEAS Transactions on Information Science and Applications, vol. 5, pp. 1001-1010, 2008.

[5] S. L. Chean, et al., "A Conceptual Framework on Constructing Effective Learning Content for Programming Novices," International Journal of Engineering \& Technology, vol. 7, no. 2, pp. 150-153, 2018.

[6] S. Ghavifekr and D. DeWitt, "Practical Applications of Blended Learning: Teaching and Learning for Higher Education," Kuala Lumpur: UM Press, 2019.

[7] A. Muna, "Principles of "Constructivism" in Foreign Language Teaching," Journal of Literature and Art Studies, vol. 7, no. 1, 2017.

[8] S. O. Bada, "Constructivism Learning Theory: A Paradigm for Teaching and Learning," IOSR Journal of Research \& Method in Education (IOSR-JRME) vol. 5, no. 6, pp. 66-70, 2015. 
[9] D. G. Lebow, "Constructivist values for instructional systems design: Five principles toward a new mindset," Educational Technology Research \& Development, vol. 41, no. 3, pp. 4-16, 1993.

[10] G. E. Hein, "Constructivist Learning Theory: The Museum and the Need of People," CECA (International Committee of Museum Educators) Conference, 1991.

[11] P. C. S. Correa and J. R. C. Kintz, "Ecosystem-based Adaptation for Improving Coastal Planning for Sea-level Rise: A Systematic Review for Mangrove Coasts," Mar. Policy, vol. 5, pp. 385-393, 2015.

[12] J. Grodotzki, et al., "Remote and Virtual Labs for Engineering Education 4.0," Procedia Manufacturing, vol. 26, pp. 1349-1360, 2018.

[13] N. N. M. A. Mokhtar, "An exploratory study of industry 4.0 in Malaysia: a case study of higher education institution in Malaysia," Indonesian Journal of Electrical Engineering and Computer Science, vol. 16, no. 2, pp. 978-987, 2019.

[14] T. L. A. Vu and T. Q. Le, "Development Orientation for Higher Education Training Programme of Mechanical Engineering in Industrial Revolution 4.0: A Perspective in Vietnam," Journal of Mechanical Engineering Research \& Developments (JMERD), vol. 42, no. 1, pp. 71-73, 2019.

[15] Widayanti, et al., "Future Physics Learning Materials Based on STEM Education: Analysis of Teachers and Students Perceptions,” Journal of Physics: Conf. Series, vol. 012021, no. 1155, 2019.

[16] M. Sirat, "Geography, Geographers and the Future Scenario: Malaysia," Conf. Ser.: Earth Environ. Sci., vol. 012001 , no. 286, 2019.

[17] A. P. Astuti, et al., "Preparing 21st Century Teachers: Implementation of 4C Character's Pre-Service Teacher through Teaching Practice,” IOP Conf. Series: Journal of Physics: Conf. Series, vol. 012109, no. 1233, 2019.

[18] A. Karim, et al., "Revisiting Innovations in ELT Through Online Classes: An Evaluation of the Approaches of 10 Minute School," Turkish Online Journal of Distance Education-TOJDE, vol. 20 no. 1, 2019.

[19] B. Endarto, et al., "Curriculum Development in the Field of Law: Facing the New Era of Industrial Revolution 4.0," Journal of Physics: Conference Series, vol. 1179, 2019.

[20] D. Suherdi, "Teaching English in the industry 4.0 and disruption era: Early lessons from the implementation of SMELT I 4.0 DE in a senior high lab school class," Indonesian Journal of Applied Linguistics, vol. 9, no. 1, pp. 67-75, 2019.

[21] F. Marian and Suparman, "Design of Student Worksheet Based On Discovery Learning to Improve the Ability of Mathematics Reasoning Students of Class VII Junior High School," Journal of Physics: Conference Series, vol. 1306, 2019.

[22] M. Slavinec, et al., "Monodisciplinarity in Science Versus Transdisciplinarity in Stem Education," Journal of Baltic Science Education, vol. 18, no. 3, pp. 435-449, 2019.

[23] N. I. A. N. Zamin, et al., "Robotic Teaching Aid for Disabled Children: A Sustainable Solution for Industrial Revolution 4.0," International Journal of Engineering \& Technology, vol. 7, no. 2, pp. 200-203, 2018.

[24] Q. Fischer, et al., "Social network as teaching material in medical school: Review and perspectives," Arch Cardiovasc Dis, vol. 111, no. 2, pp. 71-73, Feb 2018.

[25] M. R. F. Ouatik, et al., "Modeling collaborative practical work processes in an e-learning context of engineering electric education," Indonesian Journal of Electrical Engineering and Computer Science, vol. 16, no. 3, pp. 1464-1473, 2019.

[26] E. Bredo, "The social construction of learning (Handbook of academic learning: Construction of knowledge )," San Diego, CA: Academic Press, pp. 3-45, 1997.

[27] L. Louis, "An Innovative Research on the usage of Facebook in the Higher Education context of Hong Kong," Electronic Journal of E-Learning, vol. 10, no. 4, 2012.

[28] R. Dhyab and A. Varol, "Distance Education Features using Facebook," iJIM, vol. 12, no. 6, 2018.

[29] D. Jonassen, et al., "Meaningful learning with technology," Journal of Educational Technology \& Society, Upper Saddle River, NJ: Pearson, 2008.

[30] W. Banyen, et al., "A Blended Learning Model for Learning Achievement Enhancement of Thai Undergraduate Students," iJET, vol. 11, no. 4, 2016.

[31] T. Oktavia, et al., "Conceptual Model of Knowledge Management and Social Media to Support Learning Process in Higher Education Institution," TELKOMNIKA Telecommunication Computing Electronics and Control, vol. 15, no. 2, pp. 678-685, 2017.

[32] S. Young and H. Nichols, "A reflexive evaluation of technology-enhanced learning," Research in Learning Technology, vol. 25, 2017.

[33] F. Moreira, et al., "Customized X-Learning Environment: Social Networks \& knowledge-sharing tools," Procedia Computer Science, vol. 121, pp. 178-185, 2017.

[34] W. Gunawan, et al., "E-Learning through social media in the virtual learning environment," IOP Conference Series: Materials Science and Engineering, vol. 420, 2018.

[35] S. Sirkemaa and H. Varpelaide, "The Need for Digital Learning Environments," International Journal of Learning, Teaching and Educational Research, vol. 17, no. 6, pp. 167-181, 2018.

[36] D. Cole, et al., 'Using social media to support small group learning," BMC Med Educ, vol. 17, no. 1, p. $201,2017$.

[37] Supeno, et al., "Utilization of Whatsapp Application as Communication Media in Language Teaching and Learning at FBS UWKS," Journal of Physics: Conference Series, vol. 1175, 2019.

[38] H. Harrison, et al., "A Cross-Sectional Study to Describe Academics' Confidence, Attitudes, and Experience of Online Distance Learning in Higher Education,” Journal of Educators Online, vol. 14, no. 2, 2017.

[39] J. Daniel, "Massive Open Online Courses: what will be their legacy?" FEMS Microbiol Lett, vol. 363, no. 8, 2016. 
[40] Z. A. A. M. A. Bin Zamanhuri, et al., "A review on various methods of collaborative computing," Indonesian Journal of Electrical Engineering and Computer Science, vol. 16, no. 2, pp. 1002-1008, 2019.

\section{BIOGRAPHIES OF AUTHORS}
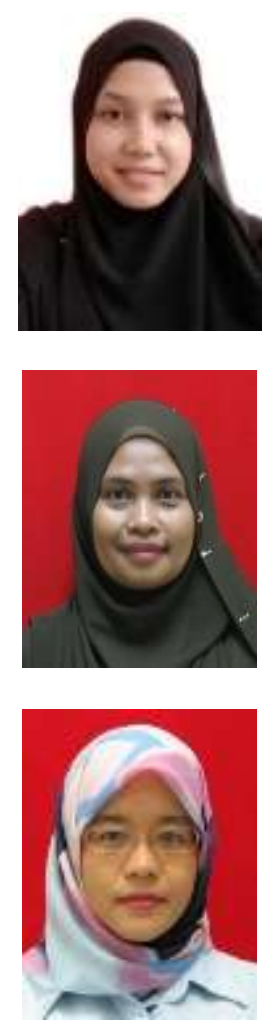

Nor Azah Mansor is pursuing his PhD study in field of Information Technology at UiTM Shah Alam, Selangor. She had a master in Information System and Management. Her research interest is in software engineering, electronic learning and social media.

Natrah Abdullah is a Senior Lecturer from the Centre of Information Technology Studies, Faculty of Computer and Mathematical Sciences, Universiti Teknologi MARA Shah Alam. Her research interest includes User Interface Design, UI/UX and usability Studies. Currently, she is a Head of Department of Information Technology Studies at Faculty of Computer and Mathematical Sciences, Universiti Teknologi MARA Shah Alam.

Hayati Abd Rahman (Dr.) is a PhD holder in Information Science at Universiti Kebangsaan Malaysia (UKM), Bangi. She is currently a senior lecturer at Universiti Teknologi MARA (UiTM), Shah Alam, Malaysia. Her area of interest is in Information Retrieval, Semantic and Linguistic Computing and Multimedia. 